\title{
Comparison of institutions
} preferred by business schools for achieving accreditation: The example of Republic of Turkey and the Turkish Republic of Northern Cyprus ${ }^{1}$

\author{
Ahmet Vecdi Can ${ }^{2}$ \\ Bilge Önal ${ }^{3}$
}

\begin{abstract}
Nowadays the competition is not only in trade but also in almost every field. So the educational institutions have to show their differences and their superiority. In this way, educational institutions have resorted to institutions that would achieve this goal by accrediting themselves in their fields in order to prove their qualifications and to improve themselves, improve their maturation and consolidation, and also provide benchmarking. Accreditation for educational institutions is an acknowledgment that educational processes and institutions are in line with specific standards. In this study, universities operating in the Republic of Turkey and the Turkish Republic of Northern Cyprus and having a Faculty of Business Administration were examined. Among the Faculty of Business Administration, those who initiate and complete the accreditation process are separated. Then it was researched to which institutions the relevant faculties are accredited or applied for. As a result, it has emerged that AACSB and IACBE are preferred. The
\end{abstract}

Özet

Rekabetin artık sadece ticarette değil hemen her alanda olması birlikte eğitim kurumları da kendi farklılıklarını ve üstünlüklerini ortaya koyma çabasına girmişlerdir. Bu yolda eğitim kurumları kalitelerini ispat etmek, ve bunun yanı sira gelişimleri için destek almak, olgunlaşma ve sağlamlaşma sağlamak ve ayrıca benchmarking için alanlarında akredite ederek bu hedefe ulaştıracak kurumlara başvurmayı tercih etmektedirler. Eğitim kurumları için Akreditasyon eğitim süreçlerinin ve kurumun belirli standartlar doğrultusunda olduğunu gösteren bir onay niteliğindedir. Bu çalışmada Türkiye ve KKTC'de faaliyet gösteren Üniversiteler incelenmiştir. İşletme Fakülteleri arasında öncelikle akreditasyon süreçlerini başlatan ve tamamlayanlar ayrıştırılmıştır. Ardından ilgili fakültelerin hangi kurumlara akredite olduğu veya olmak için başvuruda bulunduğu araştırılmıştır. Bunun sonucunda AACSB ve IACBE'nin tercih edildiği ortaya çıkmıştır. Bu iki Akreditasyon kurumunun akreditasyon süreçleri, üyelik ücretleri ve kendilerini kamuoyuna sunuşları birbirleriyle

\footnotetext{
1 This paper is a revised and extended version of a paper with the same title presented at the $8^{\text {th }}$ International Graduate Education Symposium

2 Prof. Dr., Sakarya University, Business School, Department of Business, acan@sakarya.edu.tr

${ }^{3}$ Res. Ass., Sakarya University, Business School, Department of Business, bilgeonal@sakarya.edu.tr
} 
Can, A. V., \& Önal, B. (2017). İșletme fakültelerinin akredite olmak için tercih ettiği kurumların karșılaştırılması: Türkiye Cumhuriyeti ve Kuzey Kıbris Türk Cumhuriyeti örneği. Journal of Human Sciences, 14(4), 3521-3534. doi:10.14687/jhs.v14i4.4969

accreditation processes of these two karşılaştırılmıştır. $\mathrm{Bu}$ çalş̧manın amac1 accreditation foundations, their membership ülkemizde tercih edilen akreditasyon fees and the ways in which they publicize kurumlarının birbirleriyle karşılaştırllıp, akredite themselves are compared with each other. The olmak isteyen işletme fakülteleri için bir veri aim of this study is to compare the preferred tabanı oluşturması ve kendilerine akreditasyon accreditation institutions in our country with kurumu seçerken tercih aşamasında karşılaştırma each other and to establish a data base for business faculties who want to be accredited and to provide convenience when choosing an accreditation institution.

Keywords: Accreditation; Business School; Accrediting Agency; AACSB; IACBE

(Extended English abstract is at the end of this document)

Anahtar Kelimeler: Akreditasyon; İşletme Fakültesi; Akreditasyon Kurumu; AACSB; IACBE yaparken kolaylık sağlanmasıdır.

\section{Giriş}

Akreditasyon kelimesinin kökeni Latinceye dayanmaktadır. Latince 'accredere' kelimesi dilimizde 'inanmak' anlamına gelmektedir (PONS, 2017). Akreditasyon Türk Dil Kurumuna göre 'Denklik' anlamını taşır (Türk Dil Kurumu, 2017). Fakat bir çok farklı alanlarda genel kabul görmüş mercilerin bir başka merciye spesifik bir özelliği sağlamasını belgelemesinin hukuki süreci olarak anlaşılmalıdır. Yüksekokul ve üniversitelerin akreditasyonu ise okul ve ülkelerin üzerinde lisans ve yüksek lisans eğitimlerinin değerlendirildiği bir süreçtir (Untersteller, 2017).

Bazı ülkelerde, örneğin Almanya’nın bazı eyaletlerinde gibi, 2003 yılından itibaren Bolonya süreciyle birlikte tüm lisans programlarının akredite olması koşulu getirilmiştir. Aynı zamanda akreditasyon yüksekokullardaki kalite güvencesinin dışsal bir unsuru olarak da ortaya çıkmaktadır (Turner, 2013). Yurt dışında akreditasyonun bir kalite göstergesi olarak atfedildiği gibi Türkiye’de de yükseköğretim kurumlarının akreditasyona verdiği önem artmıştır. Bu akreditasyon kurumlarının standartlarını yerine getirdikçe kalitelerini arttırdıkları ve standartlarını yükselttikleri, beklenen etkiler arasındadır.

Akreditasyon ilgili kurumlara yalnızca akredite olduktan sonra fayda sağlamaz. Kurumlar akreditasyon süreçleri içerisinde bir dönüşüme tabidirler. Bu dönüşüm sırasında karşılaşılabilecek zorluklar karşısında bulunan çözümler, sağlanan bağlantılar ve ortaklıklar önemli bir değere sahiptir. Akreditasyon kurumlar için bir kılavuz rehber niteliğindedir ve kurumlara idealizm, motivasyon, inanmışlık gibi özelliklerin yanı sıra itibar prestij ve özgüven kazandırır. Faydaları yalnızca soyut alanda değildir akreditasyonun, hem öğrenci, hem öğretim üyelerinin mobilitesini arttırır ve uluslararasılaşmayı kuvvetlendirir. Öğrenci ve öğretim üyeleri mobilitesi ile ilgili örneğin ERASMUS gibi birçok farklı uygulama olması yanı sıra, akredite olmuş kurumlar arasında protokollerin imzalanması, işbirliği gerçekleştirilmesi daha kolaylaştırılmış olacaktır. Burada Akredite olunan kurumun tanınırlı̆̆1 ve imajı önem kazanmaktadır. Uluslararası çapta eğitim birimi tanınmasa dahi, akredite olduğu kurumun kalitesi kendi kalitesini güvence altına aldığı için tanınırlı̆̆ı akreditasyon kurumuyla doğru orantıda artacaktır.

$\mathrm{Bu}$ bağlamda çalışmada Türkiye'deki İşletme Fakültelerinin mevcut akreditasyon konumları belirlenmiştir. İlgili Fakültelerin akreditasyon sürecinde hangi aşamada olduğu ve hangi akreditasyon kurumuna akredite olmaya çalıștıkları araştırılmışır. Ardından ilgili akreditasyon kurumlarının süreçleri, ücretleri ve kendilerini kamuoyuna nasıl tanıttıkları incelenmiştir. Ülkemizde tercih edilen akreditasyon kurumları, daha sonra en iyi 10 işletme okulu arasında sayılan üniversitelerin akredite oldukları kurumlarla karşılaştırılmış, gelecekte akredite olmak 
Can, A. V., \& Önal, B. (2017). İşletme fakültelerinin akredite olmak için tercih ettiği kurumların karşılaştırılması: Türkiye Cumhuriyeti ve Kuzey Kıbrıs Türk Cumhuriyeti örneği. Journal of Human Sciences, 14(4), 3521-3534. doi:10.14687/jhs.v14i4.4969

isteyen işletme fakültelerine tercihlerinde karşılaştırma yapabilmeleri için bir yol gösterilmeye çalışılmıştır.

\subsection{Literatür ve amaç}

Kavak (1999) yaptığ1 çalışmada 'öğretmen eğitiminde standartlar ve akreditasyon' isimli etkinlikte çalışmalardan bahsedip, Türkiye'deki akreditasyon çalışmaları ve ortaya koyduğu model ve süreci özetlemiştir. Adıgüzel ve Sağlam (2009) çalısmalarında öğretmen eğitiminde program standartlarının geliştirilmesinin öneminden bahsettikten sonra Türkiye'nin yanı sıra ABD ve İngiltere'deki geliştirme çalışmalarını araştırmışlardır. Bunun ardından bu program standartları ile akreditasyonun ve kalitenin bir bağlantısı olup olmadığını incelemişler ve bunun sonucunda akreditasyon standartlarının çok katı olduğunu ve kontrol odaklı olduğunu eleştirmiş akreditasyon sürecine esneklik katılması gerektiğini savunmuşlardır. Demirci ve diğerleri (2015) çalışmalarında Üniversitelerde verilen eğitimin sektör ve sektör sınavlarıly uyumluluğunu incelemişlerdir. $\mathrm{Bu}$ çalışma akreditasyonun özel sektör ve eğitim alanlarının birbirlerine entegre olduğunun altını çizdiği ve üniversite eğitiminin özel sektörün talebi karşısında eksikliklerini ortaya koyması açısından önemli bulgular içermektedir.

Süngü ve Bayrakçı (2010) çalışmalarında Bolonya Sürecinden sonra yükseköğretimde gerek Avrupa'da gerek Türkiye'de yapılan akreditasyon çalışmalarından bahsetmişlerdir. Önce Akreditasyon Süreç ve özellikleri hakkında bilgi veren Doğan (2000), çalışmasında Türkiye’de psikolojik danışman eğitimi için program düzeylerini de içeren bir akreditasyon modeli önermiştir. Doğan (1999) yaptığ1 çalışmada öğretmen eğitimindeki değişikliklerden bahsetmiş ve YÖK'ün uygulamalarını ele almıştır. Bunun yanı sıra özellikle öğretmen eğitimindeki akreditasyon konularına değinerek, yükseköğretimdeki genel akreditasyon ile öğretmen eğitimindeki akreditasyonu karşılaştırmıştır. Karslı (2014) ve diğerleri yaptıkları çalışmada akreditasyon sürecinin aslında akreditasyondan çok bir standardizasyon olduğunu iddia etmektedirler.

Young ve diğerleri (1983) çalışmalarında akreditasyonun daha iyi anlaşılabilmesi için geniş çaplı akreditasyon uygulamalarından ve kalite etkisinden bahsetmişlerdir. Batalden ve diğerleri (2002) yaptıkları çalışmada akreditasyon kuruluşlarının iş gücü gelişiminin teşvik edilmesinde önemli rol oynadığı bir model ortaya koymuşlardır. Amerika'da yapılan akreditasyon çalışmaları hakkında yayın yapan Eaton (2012), Amerika'daki akreditasyon çalışmalarının bir kalite göstergesi olduğu üzerinde durmuştur. Serrano-Velarde (2008) yaptığı çalışmada Akreditasyon ve Politika üzerine bir değerlendirme yapmıştır. Çalışmada Bolonya süreci kapsamında kalitenin güvence altına alınmasının organize edilmesi üzerinde durulmuştur.

$\mathrm{Bu}$ çalışmanın amacı ülkemizde tercih edilen akreditasyon kurumlarının birbirleriyle karşılaştırılıp, akredite olmak isteyen işletme fakülteleri için bir veri tabanı oluşturması ve kendilerine akreditasyon kurumu seçerken tercih aşamasında karşılaştırma yaparken kolaylık sağlanmasıdır

\section{Akreditasyon kurumlarının tanıtılması}

Akreditasyon Kurumları arasında bir karşılaştırmaya gidilmeden önce ilgili kurumların kuruluş tarihçeleri, misyonları, vizyonları ve kendilerini kamuoyuna nasıl tanıttıkları kısaca özetlenmelidir. Bu sebeple İşletme Fakültelerini akredite eden kurumlar sırasıyla tanıtılacaktır.

\subsection{AACSB International}

Açıllımı Association to Advance Collegiate School of Business, yani öncü üniversitelere özgü işletme okulları birliği, dünyadaki öğrencileri, akademisyenleri işletmeleri ve öncü işletme eğitimini birleştiren en büyük işletme eğitimi ağlarından biridir. Kendini bu işe adamış gönüllüler ve personel tarafından yürütülen kar amacı gütmeyen bir üyelik organizasyonu olan AACSB International, işletme okulu programlarında kalite teminatını, en güncel işletme eğitim bilgisini, fikir liderliğini ve profesyonel gelişim hizmetlerini sağlar. 
Can, A. V., \& Önal, B. (2017). İşletme fakültelerinin akredite olmak için tercih ettiği kurumların karşılaştrrılması: Türkiye Cumhuriyeti ve Kuzey Kıbrıs Türk Cumhuriyeti örneği. Journal of Human Sciences, 14(4), 3521-3534. doi:10.14687/jhs.v14i4.4969

1916 y1lında kurulan ve 90'dan fazla ülke ve bölgede 1600'ün üzerinde üye organizasyonu bulunan dünya çapında bir birleşme olan AACSB'nin merkezleri Kuzey Amerika, Pasifik Asya ve Avrupa'dadır. Tüm dünyada 795'den fazla işletme okulunu akredite eden AACSB gelecek neslin işletme yöneticilerini hazırlamak için işletme eğitiminde en yüksek kalite standartlarını güvence altına almaktadır.

AACSB International'’n misyonu işletme eğitiminde katılımı teşvik etmek, yeniliği hızlandırmak ve etkisini artırmaktır. İşletme okulları için AACSB International akreditasyon standartları ile bu misyon uyumludur. AACSB International işletme, fakülte, kurum ve öğrencilerin sürekli katılımını geliştirmek ve böylelikle, işletme uygulamaları ile işletme eğitiminin uyumlu olması için çabalamakatdır.

AACSB International bu hedefe ulaşmak amaciyla işletme eğitimini sürekli geliştirmek için yeniliği teşvik eder ve hızlandırır. Sonuç olarak işletme okulları işletmeler ve toplum üzerinde olumlu etki yaratır ve AACSB International bu etkiyi arttıracaktır.

AACSB International'ın vizyonu işletme eğitimini küresel refaha dönüştürmektir. İşletmeler ve İşletme okulları dünya ekonomisine katılan kuvvetli bir güçtür ve AACSB International - işletme okullarına, öğrencilere işletmelere ve topluma hizmet ederek - bu fayda ile tüm paydaşların birbirini daha iyi anlaması için önemli bir rol oynamaktadır.

$\mathrm{Bu}$ misyon ve vizyonları gerçekleştirerek AACSB International sayılan değerleri vurgulayacak ve modelleyecektir:

-Kalite,

-Kapsayıcılık ve Çeşitlilik,

-Küresel zihniyet,

-Etik,

-Sosyal Sorumluluk ve

-Topluluk.

$\mathrm{Bu}$ değerler AACSB International'in küresel işletme eğitim topluluğu ile gelecekteki girişimleri ve etkileşimlerini yönlendirir (AACSB International, 2017a). AACSB International kurumunda uygulanan akreditasyon süreci ve ücretleri sırasıyla gösterilmeye çalışılacaktır.

\subsubsection{Akreditasyon süreci}

AACSB International'ın Akreditasyon süreci 12 Aşamadan oluşmaktadır. Akredite olmak isteyen bir kurum bu 12 Aşamadan geçmelidir. Bu aşamalar şu şekilde gösterilir (AACSB International, 2017b):

I. Öncelikle AACSB’ye akredite olabilmek için AACSB üyesi olmak ön koşuldur.

II. Başvuruda bulunacak olan okul AACSB akreditasyon sürecine girmek istediğini belirtecek bir gösterge olarak (işletme ve/veya muhasebe akreditasyonu için) uygunluk başvurusunda bulunur.

Bir okul işletme ve muhasebe akreditasyonu için eşzamanlı başvuruda bulunabilir veya işletme akreditasyonunu aldıktan sonra muhasebe akreditasyonuna başvurabilir.

III. AACSB personeli tarafindan gözden geçirilen Uygunluk başvurusu, Başlangıç Akreditasyon Komitesi (Initial Accreditation Committee - IAC) veya Muhasebe Akreditasyon Komitesi (Accounting Accreditation Committee - AAC) başkanına kabul edilmesine yönelik bir tavsiyeyle iletilir.

IV. Başvuru onaylandıktan sonra, mentör olarak gönüllü bir işletme fakültesinin yöneticisi (örneğin dekanı) başvuru yapan okula başlangıç değerlendirme raporunu hazırlama konusunda yardımc1 olmak üzere atanır. Görevlendirilen mentör her hangi bir çıkar çatışmasının ortaya çıkmasını önlemelidir. Bu süreçte aynı zamanda AACSB Akreditasyon irtibat personeli de okula atanmaktadır. Bu irtibat personeli AACSB içerisindeki birincil irtibat kişisi olarak akreditasyonla ilgili tüm sorularla ilgilenmekle yetkilidir. 
Can, A. V., \& Önal, B. (2017). İşletme fakültelerinin akredite olmak için tercih ettiği kurumların karşılaştırılması: Türkiye Cumhuriyeti ve Kuzey Kıbrıs Türk Cumhuriyeti örneği. Journal of Human Sciences, 14(4), 3521-3534. doi:10.14687/jhs.v14i4.4969

V. Başvuran okula AACSB tarafindan uygunluk başvurusunun onaylandığını ve aynı zamanda bir mentör atandığını bildiren resmi bir yazı gönderilecektir. Bunun yanı sıra okula gönderilecek faturanın teslim alınmasından itibaren bir ay içerisinde ödenmesi gerekmektedir.

VI. Görevlendirilen mentör başvuran okulla birlikte okulun akreditasyon standartlarıla mevcut uyumunu saptamak için ve başlangıç değerlendirme raporunu geliştirmesine yardımcı olmak için çalışı. Mentör; okulun akreditasyon standartlarıyla kendini aynı hizaya getirebilecek başarılı bir planın tahsis edilen maksimum süre içerisinde geliştirmesinin beklenmesini uygun olmadığ görüşüne varırsa, bu yönde tavsiyede bulunur.

VII. Mentörün onayiyla birlikte, başvuran okul kendi başlang1ç değerlendirme raporunu stratejik planıyla birlikte bir sonraki planlanmış toplantıda incelenmek üzere IAC/AAC'ye gönderir. Başlangıç değerlendirme raporu okulun stratejik planının bir parçası olarak sunulur. ISER (Başlangıç değerlendirme raporu) genellikle bir yıl içinde tamamlansa da, tamamlanması için maksimum iki yıl süresi vardır.

VIII. IAC/AAC başlangıç değerlendirme raporunu inceler. Bu inceleme sonucunda aşağıdaki durumlardan biri ortaya çıkar

a) Planın kabulüyle birlikte okula bir öz-değerlendirme raporu oluşturması tavsiye edilir ve ardından ön akreditasyona başvurması için davet edilir (IAC/AAC hemfikir olmalıdır)

b) Plan, okulun başlangıç değerlendirme raporunun uygulama aşamasına geçilmesi yönünde bir öneri ile kabul edilir. Okul her yll standartlarla uyumluluğa doğru gelişiminin aşamasıyla ilgili ISER güncelleme raporunu komiteyi bilgilendirmek adına sunmalıdır (maksimum üç yıllık süre içerisinde). Mentör, okul ile akreditasyon için ön başvuru daveti gelene kadar çalışmaya devam eder (işletme ve/veya muhasebe için). Ön akreditasyon, başlangıç değerlendirme raporunun IAC/AAC tarafından kabul edildikten beş yıl sonra sağlanmış olmalıdır.

c) Plan, ISER'in geliştirilmesi gerektiği koşuluyla kabul edilir. Başvuruda bulunan okula raporu gözden geçirmesi ve yeniden göndermesi önerilir.

d) Başvuruda bulunan okulun verilen azami süreler içerisinde AACSB akreditasyon standartlarıyla uyumlu hale gelemeyeceği ve ön akreditasyon sürecini tamamlayamayacağı saptandığından uyum planı kabul edilmez.

IX. Yaklaşık olarak beklenen akreditasyon değerlendirme ziyaretinden iki yıl önce, bir hakem denetim başkanı (bütün ekip değil) atanır. Atanan başkan her hangi bir çıkar çatışmasından kaçınmalıdır. Başkan, okulun kendi son değerlendirme raporunu geliştirmesi ve ziyaret için program oluşturulması konusunda yardımcı olur.

X. IAC/AAC hakem denetim ekibinin diğer üyelerini atar. Ekip son öz-değerlendirme raporunu inceler ve aynı zamanda IAC/AAC tarafindan değerlendirme ve onay alındıktan sonra okula ön ziyaret mektubunu hazırlar ve gönderir.

XI. Ziyaret geçekleştirildikten sonra, hakem denetim ekibi başvuran okula, akreditasyon için tavsiyeler, erteleme veya akreditasyonun reddine ilişkin bir ziyaret raporu sunar. Rapor ve tavsiyeler uygunluk için IAC/AAC'ye gönderilir.

XII. Akreditasyona veya akreditasyonun reddine ilişkin tavsiyeler IAC / AAC tarafindan onaylanır. Tavsiyeler AACSB Yönetim Kuruluna onay için gönderilir.

\subsection{1 Ücretler}

Karar alma süreçlerinde önemli faktörlerden biri de alınan kararın maliyetleridir. Her bir seçenek için fayda maliyet analizi yapılarak katlanılacak maliyet karşısında en büyük fayda elde edilebilecek seçenek tercih edilmelidir. Bu sebeple akreditasyon kurumlarının da görünen maliyetlerinden biri olan akreditasyon ücretlerine bu kısımda yer verilmiştir. AACSB International için ücretler aşağıdaki tablodaki gibidir (AACSB International, 2017c): 
Can, A. V., \& Önal, B. (2017). İşletme fakültelerinin akredite olmak için tercih ettiği kurumların karşılaştırılması: Türkiye Cumhuriyeti ve Kuzey Kıbrıs Türk Cumhuriyeti örneği. Journal of Human Sciences, 14(4), 3521-3534. doi:10.14687/jhs.v14i4.4969

Tablo 1: Uygunluk Başvurusundan Ön Akreditasyon Ziyaretine Kadar Olan Ücret Tablosu

\begin{tabular}{|l|l|}
\hline \multicolumn{2}{|l|}{ Uygunluk başvurusundan Ön Akreditasyon Ziyaretine Kadar olan Ücretler: } \\
\hline Uygunluk başvuru ücreti: & 1.000 \\
& USD \\
\hline Başlangıç Akreditasyon Ücreti (İşletme veya Muhasebe) ${ }^{4}:$ & 5.400 \\
& USD \\
\hline Başlangıç İşletme veya Başlangıç Muhasebe Akreditasyonu Ziyaret & 14.000 \\
Başvurusu Ücreti ${ }^{5}$ : & USD \\
\hline
\end{tabular}

$\mathrm{Bu}$ tabloda görüldüğü gibi süreç ilerledikçe ücretlerde de bir artış meydana gelmektedir. Akreditasyon başvurusunda bulunacak olan kurumların bu ücretlerin sadece direkt olarak AACSB International'a ödeneceğini ve bunların yanı sıra Akreditasyon standartları ile uyum sağlamak için çok daha fazla maliyetlerle karşılaşılabileceğini göz önünde bulundurulmalıdır.

Tablo 2: Akredite Olmuş Kurumar İçin Ücret Tablosu

\begin{tabular}{|l|l|}
\hline Akredite olmuş Kurumlar için Ücretler: \\
\hline Y1llık Akreditasyon Ücreti (İşletme): & 5.400 \\
& USD \\
\hline Y1llık Akreditasyon Ücreti (İşletme ve Muhasebe): & 8.700 \\
& USD \\
\hline
\end{tabular}

Kurumlar Akredite olduktan sonra, ylllı olarak akreditasyon ücretleri ödemekle yükümlüdür. Yukarıdaki tabloda bu ücretler görülmektedir. Yıllık Akreditasyon ücreti ön akreditasyon ücreti ile aynı seviyede. Eğer kurum aynı anda hem İşletme hem de Muhasebe alanında akredite olmayı başarmıs ise üyelik ücreti ikiye katlanmıyor, bunun aksine ortalama \%38'lik bir düşüşle 8.700 Amerikan Dolarına iniyor. Burada kurumların hem işletme hem de Muhasebe alanında akredite olmalarını teşvik edici bir etki olabileceği düşünülebilir.

\subsection{IACBE}

Açllımı International Assembly for Collegiate Business Education, yani Üniversitelere özgü işletme eğitimi için uluslararası meclis, olan IACBE 1997 yılında cumhurbaşkanlarının, başkanların, üst düzey akademik yöneticilerin, işletme dekanlarının, müdürler ve bölüm başkanlarının girdi ve kaynaklara bağlı olarak katı kurallar koyan bir akreditasyon sürecinden ziyade bir misyon tarafindan yönlendirilen ve çıktı temelli akreditasyon süreci talepleri üzerine kurulmuştur.

IACBE kurulmadan önce Birleşik Devletlerdeki 4 yıllık Yüksekokulların ve Üniversitelerin çoğunluğu mevcut akreditasyon kuruluşları tarafından tanınmamıştı ve akreditasyon kurumlarının yüksek standartları sebebiyle tanınamayacaktı. Aynı zamanda Birleşik Devletlerin dışında kalan yüzlerce yükseköğretim kurumu işletme eğitimleriyle ilgili özel akreditasyona hak kazanamadı. Günümüze kadar IACBE önceliği öğretme ve öğrenmede mükemmellik olan yüksekokul ve üniversitelerdeki işletme ve yönetim eğitimi için, sonuç odaklı öncü profesyonel akreditasyon temsilcisi haline gelmiştir.

Dünya genelinde yüzlerce kurum ve kampüs üyesi bulunan IACBE, Birleşik Devletler, Avrupa, Orta Doğu, Orta Amerika ve Güney Amerika'da 1300'den fazla işletme ve işletme benzeri programı akredite etmiştir (IACBE, 2017a).

\footnotetext{
${ }^{4}$ Ön akreditasyon süreci boyunca yıllık olarak ödenir

5 Ön akreditasyon başvuru talebinin ardından
} 
Can, A. V., \& Önal, B. (2017). İşletme fakültelerinin akredite olmak için tercih ettiği kurumların karşlaştırılması: Türkiye Cumhuriyeti ve Kuzey Kıbrıs Türk Cumhuriyeti örneği. Journal of Human Sciences, 14(4), 3521-3534. doi:10.14687/jhs.v14i4.4969

IACBE'nin misyonu, hem ön lisans hem lisans seviyesinde, işletme programlarında uzmanlaşmış akreditasyon yardımıyla, dünya çapında yükseköğretim kurumlarındaki işletme eğitiminin mükemmelliğini teşvik ve takdir etmektir.

IACBE'nin vizyonu, işletme ve yönetim eğitiminde misyon odaklı ve sonuç tabanlı program akreditasyonunda lider olmak ve dünya çapında öğrenci odaklı olan yüksek öğretim kurumlarının işletme akreditasyon gövdesini oluşturmaktır (IACBE, 2017b). IACBE kurumunda uygulanan akreditasyon süreci ve ücretleri sırasıyla gösterilmeye çalışlacaktır.

\subsubsection{Akreditasyon Süreci}

IACBE Akreditasyon sürecini ilk defa akredite olacaklar için sekiz kısa adımda özetlemiştir (IACBE, 2017c):

I. Akademik Isşletme birimi IACBE'nin eğitim üyesi olur.

II. Akademik İşletme birimi adaylık belgelerini hazırlar ve bir adaylık ziyaretine tabi tutulur.

III. IACBE Komisyon Heyeti akademik İşletme birimi için adaylık değerlendirmesini yürütür.

IV. Akademik İşletme birimi Akreditasyon için aday olur.

V. Akademik İşletme birimi bir bireysel çalışma hazırlar ve bir saha ziyaretine tabi tutulur.

VI. IACBE Komisyon Heyeti akademik işletme birimi için akreditasyon değerlendirmesini yürütür.

VII. IACBE Komisyon Heyeti Akademik İşletme Biriminin İşletme Programlarının akreditasyon durumunu belirler.

$\mathrm{Bu}$ süreci biraz daha iyi anlamak için biraz detaylandırmak gerekmektedir. IACBE'nin eğitim üyesi olmak için öncelikle üyelik başvurusunu yapıp ücretler ödenmiş olmalıdır. Eğitim üyeliğine kabul edildikten sonra, kapsamlı sonuç değerlendirmesi planını geliştirmeye yönelik seminerlere katılıp ardından adaylık statüsü için başvuru evrakları gönderilmelidir. Adaylık ziyaretine ev sahipliği yaptıktan sonra adaylık ziyareti raporunu alınmalı ve cevaplanmalıdır. Komisyon heyeti tarafından akademik işletme biriminin adaylık durumu kararlaştırılır ve adaylık statüsü verilmesi kararına varıldığı takdirde süreç devam eder.

Adaylık statüsüne kabul edilen akademik işletme birimi ilk akreditasyon için başvuru evraklarını gönderir ve saha ziyareti planlanır. Etkili bir bireysel çalışma hazırlamak için bir seminere katıldıktan sonra, birim bireysel çalısmayı hazırlar ve gönderir. Birim akreditasyon saha ziyaretine tabi tutulduktan sonra saha ziyareti raporunu teslim alınmalı ve cevaplanmalıdır. Son olarak Komisyon heyeti akreditasyonu değerlendirir ve işletme biriminin işletme programlarının akreditasyon durumunu belirler.

\subsection{1 Ücretler}

IACBE Akreditasyon sürecinde karşlaşılabilecek maliyetler ile ilgili web sitesinde AACSB'ye göre daha fazla bilgiye yer vermiştir. Ayrıca dikkat çeken önemli bir nokta da üye olmak isteyen birimler için tarihlere göre farklllık gösteren ücretler bildirmiştir.

Tablo 3: Yeni Üyeler için Üyelik Ücreti Tablosu

\begin{tabular}{|l|l|}
\hline 1 Ocak -28 Şubat & 2.450 USD \\
\hline 1 Mart -30 Nisan & 1.960 USD \\
\hline 1 Mayıs -30 Haziran & 1.470 USD \\
\hline 1 Temmuz -31 Ağustos & 980 USD \\
\hline 1 Eylül - 31 Ekim & 490 USD \\
\hline 1 Kasım -31 Aralık & $\begin{array}{l}2017 \text { den feragat } \\
\text { edilmiş ücretin kalanı }\end{array}$ \\
\hline
\end{tabular}


Can, A. V., \& Önal, B. (2017). İşletme fakültelerinin akredite olmak için tercih ettiği kurumların karşlaştırılması: Türkiye Cumhuriyeti ve Kuzey Kıbrıs Türk Cumhuriyeti örneği. Journal of Human Sciences, 14(4), 3521-3534. doi:10.14687/jhs.v14i4.4969

2018 y1lı için IACBE uygulayacağ1 yıllık üyelik ücretinin 2.550 USD olacağını açıklamıştır. Yukarıda tabloda gösterilen ücretlerin yanı sıra akredite olmuş üyeler için yıllık 500 USD ayrıca ödeme yükümlülüğü bulunmaktadır (IACBE, 2017d).

Yıllık ödenmesi gereken üyelik ücretlerinin yanı sıra aynı zamanda başvuruda bulunan kurumun bazı başvuru ücretleri de ödemesi gerekmektedir.

Tablo 4: Başvuru Ücretleri Tablosu

\begin{tabular}{|l|l|}
\hline Adaylık statüsü için başvuru ücreti & 1.200 \\
& USD \\
\hline İlk Akreditasyon ve Akreditasyon yenilemesi için başvuru ücreti & 1.700 \\
& USD \\
\hline
\end{tabular}

Akreditasyon sürecinde de bahsedildiği gibi katlanılması gereken seminerlerin ücretleri ve saha ziyaretlerinden kaynaklanacak olan ücretler de göz ardı edilmemelidir.

\subsection{ACBSP}

1988 yllinda kurulan Accreditation Council For Business Schools and Programs, yani İşletme okulları ve programları için akreditasyon konseyi günümüzde 764 üniversitenin işletme lisans programını akredite etmiştir. Overland Park, Kansas'ta faaliyetlerine başlayan kurum, zamanla tüm dünyaya yayılmışıtır.

ACBSP'nin misyonu, sürekli gelişmeyi teşvik etmek ve dünya çapında ticari eğitim programlarının akreditasyonunda mükemmelliği yakalamaktır. Aynı zamanda akademik çalışmaların geliştirilmiş öğretimi kolaylaştırdığını vurgular. ACBSP eğitim kurumlarının öğretim ve araştırma arasında makul bir denge kurmaları konusunda teşvik edici bir rol üstlenmiştir. Ayrıca, eğitiminin kalitesini arttırmak amacıyla iş dünyası ve üniversite işbirliğine önem vermektedir. Kurumun vizyonu tüm dünyadaki kaliteli işletme programlarının akredite edilmiş olması yönündedir. İş dünyası ve fakülteler arasındaki iş birliğine verilen önem doğrultusunda dünya çapında üniversiteler arası ve iş dünyası issbirlikleri hedefini benimsemisstir (Accreditation Council for Business Schools and Programs, 2016). ACBSP kurumunda uygulanan akreditasyon süreci ve ücretleri sırasıyla gösterilmeye çalışlacaktır.

\subsubsection{Akreditasyon Süreci}

ACBSP kurumunun akreditasyon süreci yedi adımda özetlenebilmektedir:

I. Akademik İşletme birimi ACBSP'nin üyesi olur.

II. Adaylık Formu doldurulup üyelik ücreti ile birlikte gönderilir.

III. Online Raporlama Platformu üzerinden bir ön anket gönderilir.

IV. Boşluk analizi yapmak ve başvuruda bulunan kurumun tümüyle bireysel çalışma sürecine geçmesi yönünde kurumu yetkilendirmesi için bir mentör atanır.

V. Bireysel çalışma tamamlanır ve sunulur.

VI. Kuruma yapılacak saha ziyareti için tarih belirlenir.

VII. Yapılan saha ziyaretinin tarihine göre sonuçlar nisan veya kasım ayında açıklanır.

\subsection{1 Ücretler}

ACBSP akredite olmak isteyen bir kurumun hem Amerikan Birleşik Devletleri içerisinde hem de dışarısında olmak üzere iki farklı tahmini ücret planı hazırlamıştır. Tablo 5'de ABD dışındaki bir kurumun tahmini akreditasyon ücretleri verilmiştir. 
Can, A. V., \& Önal, B. (2017). İşletme fakültelerinin akredite olmak için tercih ettiği kurumların karşlaştırılması: Türkiye Cumhuriyeti ve Kuzey Kıbrıs Türk Cumhuriyeti örneği. Journal of Human Sciences, 14(4), 3521-3534. doi:10.14687/jhs.v14i4.4969

Tablo 5: ACBSP Ücretleri Tablosu

\begin{tabular}{|c|c|}
\hline \multicolumn{2}{|l|}{ 1. Y11 Ücretleri } \\
\hline Üyelik & $\begin{array}{l}2.000 \\
\text { USD }\end{array}$ \\
\hline Adaylık Başvuru Ücreti & $\begin{array}{l}1.250 \\
\text { USD }\end{array}$ \\
\hline Mentör Ücreti & 500 USD \\
\hline Mentörün Masrafları (Ulaşım, Konaklama, Yeme, İçme vb.) & $\begin{array}{l}2.550 \\
\text { USD }\end{array}$ \\
\hline \multicolumn{2}{|l|}{ 2. Y11 Ücretleri } \\
\hline Üyelik & $\begin{array}{l}2.600 \\
\text { USD }\end{array}$ \\
\hline Eylem Planının Sonuçlandırılması & 500 USD \\
\hline Akreditasyon Ücretinin Yarıs & $\begin{array}{l}1.250 \\
\text { USD }\end{array}$ \\
\hline \multicolumn{2}{|l|}{ 3. Y11 Ücretleri } \\
\hline Üyelik & $\begin{array}{l}2.600 \\
\text { USD }\end{array}$ \\
\hline Saha Ziyareti & $\begin{array}{l}7.700 \\
\text { USD }\end{array}$ \\
\hline
\end{tabular}

Burada göze çarpan, ACBSP kurumunun akredite olmak isteyen eğitim birimine mentör ve saha ziyaretlerinde karşılaşılabilecek ulaşım, konaklama gibi masraflar da dahil olacak şekilde bir plan hazırlamış olmasıdır. Önemli olan bir diğer nokta ise diğer kurumların mentörleri, bu görevi gönüllülük esasına dayalı olarak yapmakta iken, bu akreditasyon kurumunun mentörlerinin bir ücret almalarıdır.

\subsection{EQUIS}

EQUIS EFMD'nin, European Foundation for Management Development, yani Avrupa İşletme Geliştirme Vakfı, sunduğu akreditasyon hizmetlerinden bir tanesidir. EFMD Quality Improvement System (EQUIS) misyonunu EFMD'ye uygun olarak uluslararası işletme eğitiminin standartlarını yükseltilmesi yönünde belirlemiştir. EQUIS akreditasyonu, yönetişim, programlar, öğretim üyeleri, öğrenciler, araştırmalar ve her şeyden önce kurumsal bağlantılar, uluslararasılaşma ve etik, sorumluluk ve sürdürülebilirlik açısından bir dizi uluslararası standartlara karşı okulun kıyaslanması için titiz bir kalite geliştirme sürecini garanti etmektedir. EQUIS 1997'den bu yana 40 ülkede 160'1n üzerinde kurumu akredite etmiştir (EFMD, 2017a). EFMD kurumunda uygulanan akreditasyon süreci ve ücretleri sırasıyla gösterilmeye çalısılacaktır.

\subsubsection{Akreditasyon Süreci}

EQUiS Akreditasyon süreci 10 adımda kısaca özetlenebilmektedir:

I. Başvurunun yapılması

II. Bilgilendirme Ziyaretinin gerçekleştirilmesi

III. Bilgilendirme Ziyareti Raporunun hazırlanmas1

IV. Ön-Uygunluk Önerisinin sunulmas1

V. Uygunluk Başvurusunun yapılması

VI. Uygunluk

VII. Ön-Değerlendirme Önerisinin sunulması

VIII. Öz-Değerlendirme Raporunun oluşturulması

IX. Hakem Denetim Raporunun hazırlanması 
Can, A. V., \& Önal, B. (2017). İşletme fakültelerinin akredite olmak için tercih ettiği kurumların karşılaştırılması: Türkiye Cumhuriyeti ve Kuzey Kıbrıs Türk Cumhuriyeti örneği. Journal of Human Sciences, 14(4), 3521-3534. doi:10.14687/jhs.v14i4.4969

X. Akreditasyon Sürecinin tamamlanması

Kurumun paylaştığı bilgiler doğrultusunda ilk beş adımın tamamlanmasının normal şartlar altında iki yıldan daha kısa bir zaman alması beklenirken, eğitim kurumunun hakem denetim ziyareti aşamasına gelmesinin en fazla iki yıl sürmesi planlanmaktadır. Hakem denetim raporunun hazırlanması 10 haftalık bir zaman dilimini kapsarken, akreditasyon sürecinin üç ila beş yıl arasinda tamamlanması beklenmektedir (EFMD, 2017b).

\subsection{1 Ücretler}

EQUIS akreditasyonuna sahip olabilmek için kurumun web sitesinde paylaştığı ücretler Tablo 6'da gösterilmiştir.

Tablo 6: EQUIS Ücret Tablosu

\begin{tabular}{|l|l|}
\hline $\begin{array}{l}\text { Başvuru Ücreti (Yeniden akreditasyona başvuracak okullar için de } \\
\text { ödenmesi gerekmektedir) }\end{array}$ & $10.050 €$ \\
\hline $\begin{array}{l}\text { Uygunluk Ücreti (Yalnızca ilk akreditasyona başvuracak okullar tarafindan } \\
\text { önemesi gerekmektdir) }\end{array}$ & $10.050 €$ \\
\hline Değerlendirme Ücreti & $16.750 €$ \\
\hline Beş Yıllık Akreditasyon Ücreti & $16.750 €$ \\
\hline Üç Ylllk Akreditasyon Ücreti & $10.050 €$ \\
\hline
\end{tabular}

Akreditasyon ücretinin ödenmesi ile ilgili kurum iki farklı seçenek sunmuştur. Bunlardan ilki akreditasyon ücretinin, akreditasyon kurulunun kararından en geç 30 gün içerisinde yıllık 3.350 $€$ tutarında taksitler şeklindedir. Bir diğer seçenek ise Akreditasyon kurulunun EQUIS belgesini verdikten sonra 30 gün içerisinde ödenmesi yönündedir.

\section{Türkiye ve Kuzey Kıbris'ta tercih edilen akreditasyon kurumları}

Bünyesinde İşletme Fakültesi barındıran Kuzey Kıbrıs'ta bir ve Türkiye'de 28 Üniversite tespit edilmiştir. Araştırmaya devlet, vakıf ve özel üniversiteler dahil edilmiştir. Toplamda 29 İşletme Fakültesinden 21'inin herhangi bir Akreditasyon Kurumu tarafindan akredite edilmediği ve herhangi bir akreditasyon kurumuna üyeliği bulunmadığ1 tespit edilmiştir. Akredite olmuş kurumlar arasında İstanbul Teknik Üniversitesinin İşletme Mühendisliği ve Endüstri Mühendisliği bazında Mühendislik alanında akreditasyon çalışmaları yapan ABET (Accreditation Board for Engineering and Technology), yani Mühendislik ve Teknoloji için Akreditasyon Kurumu, işletme fakültelerini ve işletme bölümünü akredite etmemesi sebebiyle değerlendirme dışı bırakılmıştır (ABET, 2017).

Kalan yedi işletme fakültesinden biri devlet biri vakıf üniversitesi olmak üzere ikisinin AACSB Kurumu ve Kıbrıs'ta bulunan bir özel üniversitenin işletme fakültesinin ise IACBE tarafından akredite edilmiş olduğu anlaşılmıştır. İkisi Vakıf ikisi ise Devlet Üniversitesi bünyesinde bulunan 4 İşletme Fakültesi ise AACSB Üyeliği statüsünde AACSB Akreditasyonunu almak üzere çalışmalarına başladığı tespit edilmiştir.

AACSB ve IACBE birbirleri ile karşılaştırıldıklarında, IACBE'nin çok daha kısa sürede sayıca AACSB'nin çok üzerinde kurumu akredite ettiği göze çarpan ilk detaylardandır. Bu durum kurumun akreditasyon sürecinin daha esnek olduğu algısını yaratmaktadır. Akreditasyon süreçleri incelendiğinde bu durum desteklenmektedir. AACSB kurumunun akreditasyon süreci daha zorludur ve kurumu geliştirmeye, ilerletmeye yönelik standartların erişilmeye çalışılması ile birlikte süreç boyunca dahi kuruma artı değerler katmaktadır.

İki kurumun ücretleri karşılaştırıldığı takdirde, akreditasyon süreci maliyetinin hesaplanabilir kısmı ortaya çıkmaktadır. AACSB ve IACBE için akreditasyon süreçlerini yedi yıl içerisinde tamamladıkları takdirde web sitelerinde paylaştıkları bilgiler doğrultusunda örnek 
Can, A. V., \& Önal, B. (2017). İşletme fakültelerinin akredite olmak için tercih ettiği kurumların karşlaștırılması: Türkiye Cumhuriyeti ve Kuzey Kıbrıs Türk Cumhuriyeti örneği. Journal of Human Sciences, 14(4), 3521-3534. doi:10.14687/jhs.v14i4.4969

hesaplamalar yapılmaya çalışılmıştır. AACSB kurumuna akredite olmak isteyen bir eğitim birimi uygunluk başvuru ücreti olarak 1.000 USD'ın yanı sıra yedi yıl boyunca toplamda ön akreditasyon ücreti olarak 37.800 USD ödemesi gerekmektedir. Bunların yanı sıra ön akreditasyon ziyareti başvuru ücreti olarak 14.000 USD’lık bir ücret ortaya çıkmaktadır. Kurumun rakamsal olarak paylaştı̆̆ bu ücretler toplandığında 52.800 USD, yani yaklaşık olarak 184.800 TL $^{6}$ tutarında bir toplam ödeme hesaplanmalıdır. Burada kurum yalnızca bu tutarda bir harcama yaparak akreditasyon ile ilgili tüm maliyetleri hesaba kattığı yanılgısına düşmemelidir. Akreditasyon süreci boyunca kuruma destek verecek mentörün ve kuruma gerçekleştirilecek diğer tüm ziyaretlerdeki konaklama, ulaşım, yeme ve içme gibi tüm masraflar eğitim birimine ait olacaktır. Ayrıca bunların yanı sıra eğitim birimi, farklı ülkelerde düzenlenecek olan toplantılara katılarak, yine katılım ücretleri, ulaşım, konaklama ve diğer masraflar ile karşı karşıya kalacaktır?

IACBE kurumuna akredite olmak isteyen eğitim biriminin karşılaşacağ ü ücretler incelendiğinde, adaylık için 1.200 USD ve akreditasyon başvuru ücreti olarak 1.700 USD'ın yanı sıra toplamda 17.850 USD üyelik ücreti ödenmesi beklenmelidir. 20.750 USD, yani 72.625 TL olarak gözüken bu harcamalar AACSB'nin neredeyse yarısı tutarındadır. Fakat yine göz ardı edilmemesi gereken, ziyaretler sırasında karşılaşılabilecek harcamalardır.

Burada sıralanan ücretlerin yanı sıra, ilgili kurumun standartlarına ulaşabilmek için kuruma yapılması gereken yatırımlar da olabilmektedir. Örneğin akreditasyon kurumunun belirli standartlarına erişilebilmesi için bir laboratuvarın kurulması ve bu laboratuvarın beraberinde getirdiği harcamalar da göz ardı edilmemelidir. Yapılan bu harcamaların eğitime ve öğrenciye birer yatırım niteliğinde olduğunu ve öğrenim çıktısı kalitesi arttırdığ1 düşünülecek olursa, maliyeti düşük olan kurum değil, fayda-maliyet oranı en yüksek olan kurum değerlendirmeye alınmalıdır.

\section{Dünya çapında en iyi 10 işletme okulunun akredite olduğu kurumlar}

QS World University Rankings by Subject 2016 y1lina göre, yani alana göre üniversite sıralaması 2016 yılı için aşağıdaki tabloda gösterilmiştir. Bu tabloya ilgili okulların hangi kurumlar tarafindan akredite edildiği eklenmiştir ( QS Quacquarelli Symonds Limited, 2017):

Tablo 7: 2016 Yili İşletme Alaninda En Başarili 10 Üniversite

\begin{tabular}{|l|l|l|l|}
\hline Sira & Üniversite & Ülke & Akreditasyon \\
\hline 1. & Harvard University & ABD & AACSB \\
\hline 2. & London Business School & İngiltere & $\begin{array}{l}\text { EQUIS, } \\
\text { AACSB, AMBA }\end{array}$ \\
\hline 3. & $\begin{array}{l}\text { Institut Européen d'Administration } \\
\text { des Affaires }\end{array}$ & Fransa & $\begin{array}{l}\text { EQUIS, } \\
\text { AACSB, AMBA }\end{array}$ \\
\hline 4. & $\begin{array}{l}\text { Massachusetts Institute of } \\
\text { Technology }\end{array}$ & ABD & $\begin{array}{l}\text { NEASC, } \\
\text { AACSB }\end{array}$ \\
\hline 5. & University of Pennsylvania & ABD & AACSB \\
\hline 6. & Stanford University & ABD & AACSB \\
\hline 7. & University of Oxford & İngiltere & EQUIS, AMBA \\
\hline 8. & University of Cambridge & İngiltere & EQUIS, AMBA \\
\hline 9. & $\begin{array}{l}\text { London School of Economics and } \\
\text { Political Science }\end{array}$ & İngiltere & CPA, ACCA \\
\hline 10. & University of California, Berkeley & ABD & AACSB \\
\hline
\end{tabular}

\footnotetext{
${ }^{6} 1 \mathrm{USD}=3,5 \mathrm{TL}$ alınmıştır.

${ }^{7}$ Örneğin 21 Ağustos 2017 tarihinde Avusturalya'da gerçekleştirilecek olan bir toplantılın katılım ücreti 695 USD, yani yaklaşık olarak 2.450 TL'dir.
} 
Can, A. V., \& Önal, B. (2017). İşletme fakültelerinin akredite olmak için tercih ettiği kurumların karşlaștırılması: Türkiye Cumhuriyeti ve Kuzey Kıbris Türk Cumhuriyeti örneği. Journal of Human Sciences, 14(4), 3521-3534. doi:10.14687/ihs.v14i4.4969

Dünya çapında en iyi işletme okulları arasında sayılan on üniversitenin yedisinin AACSB'yi tercih ettiği görülmektedir. Bunun yanı sıra üç Üniversitenin de önemli bir işletme akreditasyon birleşimi olarak "EQUIS, AACSB ve AMBA"'dan üçlü akreditasyona sahip olduğu göze çarpmaktadır. Türkiye'de bulunan üniversitelerin işletme fakültelerinin de dünya çapında en iyi okullar arasında sayılan bu okulların tercih ettiği kurumları göz önünde bulundurarak kendi kalitelerini bu on üniversiteye yaklaştırma çabası içerisinde olduğu düşünülebilir.

\section{Sonuç ve Değerlendirme}

Türkiye'deki işletme fakültelerinin kendi web sitelerinde paylaştıkları bilgiler doğrultusunda akredite olmak için çoğunlukla AACSB kurumunu tercih ettiği gözlemlenebilmektedir. Kuzey Kıbrıs'ta yalnızca Girne Amerikan Üniversitesinin bünyesinde bir İşetme Fakültesi barındırdığ1 ve bu Fakültenin ise IACBE kurumunu akredite olmak için tercih ettiği sonucu ortaya çıkmıştır.

Her iki kurumun kendilerini kamuoyuna sunumu incelendiğinde, AACSB kurumunun bir işletme fakültesini akredite etmesi için kurallı ve belirli standartlara uyarak değerlendirme sürecine sahip olduğu anlaşılmıştır. IACBE ise kendini tanıtırken dahi bu kurallı ve standartlardan oluşan akreditasyon sürecine karşı olarak ortaya çıkan bir kuruluş olduğunu ifade etmektedir. Her ne kadar iki kuruluşun da çabası işletme okulları tarafından akredite olunmak istenen ve tercih edilen kurumlar olmak olsa dahi, Tablo 7'de dünya çapında en başarılı işletme okullarına bakıldığında \%70'inin AACSB kurumunu tercih ettiği ve IACBE'nin hiçbiri tarafindan tercih edilmediği görülmektedir.

Her iki kurumun üyelik ücretleri karşılaştırıldığında IACBE'nin yılllk ücretinin AACSB'nin neredeyse yarısı kadar olduğu fakat başvuru ücretlerinin $\% 20$ daha yüksek olduğu gözlemlenmektedir. Süreç boyunca karşılaşılabilecek ödemelerin ilk etapta dahi AACSB kurumunda IACBE'nin iki katı oranında olduğu görülmektedir. Burada göz ardı edilmemesi gereken bir nokta ise, AACSB'nin daha kuralc1 ve standartlara uygun bir akreditasyon süreci istemesi sebebiyle akreditasyon süreci boyunca bu standartlara ulaşabilmek için IACBE'nin esnek hatlı akreditasyon sürecinden daha fazla maliyete katlanılması beklenebilir.

Akreditasyonu bir kalite göstergesi olarak değerlendirecek olursak, dünya çapında kalitesini ve başarısını ispat etmiş okulların tercih ettiği kurumların bu göstergeyi daha iyi yansıttı̆̆ düşünülmelidir. Bu sebeple akreditasyon kurumları maliyetler ve standartların yüksekliği ile değil faydaları ile değerlendirilmelidir ve her ne kadar yüksek olursa olsun bunlara katlanıldığında daha büyük bir fayda elde edileceğinin farkında olunmalıdır.

\section{Kaynakça}

QS Quacquarelli Symonds Limited. (2017, 04 09). QS Quacquarelli Symonds Limited. QS Quacquarelli Symonds Limited: https://www.topuniversities.com/university-rankings/university-subjectrankings/2017/business-management-studies adresinden alınmıştır

AACSB International. (2017, 04 10). AACSB International. AACSB International: AACSB International adresinden alınmıştır

AACSB International. (2017, 04 10). AACSB International. AACSB International: http://www.aacsb.edu/accreditation/process adresinden alınmıştır

AACSB International. (2017, 04 10). AACSB International. AACSB International: http://www.aacsb.edu/accreditation/fees adresinden alınmıştur

ABET. (2017, 04 10). ABET. ABET: http://www.abet.org/ adresinden alınmıştır

Accreditation Council for Business Schools and Programs. ACBSP - Global Business Accreditation. 2016. http://www.acbsp.org/?page=about_us (06 22, 2017 tarihinde erişilmiştir).

Adıgüzel, A., ve Sağlam, M. (2009). Öğretmen eğitiminde program standartları ve akreditasyon. Inonu University Journal of the Faculty of Education, 10(3), 83-103. 
Can, A. V., \& Önal, B. (2017). İșletme fakültelerinin akredite olmak için tercih ettiği kurumların karșılaştırılması: Türkiye Cumhuriyeti ve Kuzey Kıbris Türk Cumhuriyeti örneği. Journal of Human Sciences, 14(4), 3521-3534. doi:10.14687/jhs.v14i4.4969

Batalden, P., Leach, D., Swing, S., Dreyfus, H., \& Dreyfus, S. (2002). General Competencies and Accreditation in Graduate Medical Education. Health Affairs, 103-11.

Demirci, Doğuş; Kıymaz, Merve ve Ağsakal, Ahmet (2015), "Yükseköğretimde Verilen Muhasebe Eğitiminin Muhasebe Mesleğine Giriş Sınavlarına Katkısı: Devlet Üniversiteleri İşletme Ve Muhasebe Bölümleri Üzerine Bir Araştırma", Gümüşhane Üniversitesi Sosyal Bilimler Elektronik Dergisi, 13, 264-280, DOİ - 10.17823/gusb.195

Doğan, İ. (1999). Eğitimde Kalite ve Akreditasyon Sorunu: Eğitim Fakülteleri Üzerine Bir Deneme. Kuram ve Uygulamada Eğitim Yönetimi, 5(4), 503-520.

Doğan, S. (2000). Psikolojik Danışman Eğitiminde Akreditasyonun Gereği ve Bir Model Önerisi. Türk Psikolojik Danışmanlık ve Rehberlik Dergisi, 2(14), 31-38.

Eaton, J. S. (2012). An Overview of U.S. Accreditation. Washington: Council for Higher Education Accreditation.

EFMD. «About EFMD.» efmd.org. 2017. http://www.efmd.org/images/stories/efmd/downloadables/EFMD/About_EFMD.pdf (06 28, 2017 tarihinde erişilmiştir).

$\begin{array}{llll}\text { «EQUis } & \text { Process } & \text { Manual.» } & \text { efmd.org. }\end{array}$ https://www.efmd.org/images/stories/efmd/EQUIS/2017/EQUIS_Process_Manual.pdf (06 28, 2017 tarihinde erişilmiştir).

Hilmi Süngü, M. B. (2010). Bolonya Süreci Sonrası Yükseköğretimde Akreditasyon Çalışmaları. Türk Eğitim Bilimleri Dergisi, 8(4), 895-912.

IACBE. (2017, 04 10). IACBE. IACBE: http://iacbe.org/about-iacbe.asp adresinden alınmıştır

IACBE. (2017, 04 10). IACBE. IACBE: http://iacbe.org/mission.asp adresinden alınmıstır

IACBE. (2017, 04 10). IACBE. IACBE: http://iacbe.org/accreditation-process.asp adresinden alınmıştır

IACBE. (2017, 04 10). IACBE. IACBE: http://iacbe.org/costs-fees.asp adresinden alınmıştır

Karslı, M. D., Yıldız, K., Akgün, N., \& Cerit, Y. (2014). Yeni Yönetim Teorilerinin Bazı Kavramları Açısından Eğitim Fakültelerinin Akreditasyon Uygulamasının Analitik Olarak Değerlendirilmesi. Kuram ve Uygulamada Eğitim Yönetimi, 27(27), 347-358.

Kavak, Y. (1999). Öğretmen Eğitiminde Yeni Bir Yaklaşıma Doğru: Standartlar ve Akreditasyon. Kuram ve Uygulamada Eğitim Yönetimi(19), 313-324.

PONS GmbH. (2017, 04 10). PONS. PONS: http://de.pons.com/\%C3\%BCbersetzung/latein-deutsch adresinden alınmıştır

Serrano-Velarde, K. (2008). Evaluation, Akreditierung und Politik. Wiesbaden: VS Verlag für Sozialwissenschaften.

Turner, G. ile Röportaj (2013, 08 30).

Türk Dil Kurumu. (2017, 04 10). Türk Dil Kurumu. Türk Dil Kurumu: http://www.tdk.gov.tr/index.php?option=com_gts\&arama=gts\&guid=TDK.GTS.58eb413b7098 e 0.23519763 adresinden alınmıştır

Untersteller, I. (2017, 04 10). Bundesverfassungsgericht. Bundesverfassungsgericht: http://www.bundesverfassungsgericht.de/SharedDocs/Entscheidungen/DE/2016/02/ls201602 17_1bvl000810.html adresinden alınmıştur

Young, K. E. (1983). Understanding Accreditation: Contemporary Perspecties on Issues and Practices in Evaluating Education Quality. San Francisco: Jossey-Bass, Inc.

\section{Extended English Abstract}

Nowadays the competition is not only in trade but also in almost every field. So the educational institutions have to show their differences and their superiority. In this way, educational institutions have resorted to institutions that would achieve this goal by accrediting themselves in their fields in order to prove their qualifications. There are many different institutions that accredit different faculties in different disciplines. So every faculty even every department has to choose the best for itself. The accreditation institution is very important for the image of the educational unit. It can use the accreditation as a promotion instrument for attract students' attention. 
Can, A. V., \& Önal, B. (2017). İșletme fakültelerinin akredite olmak için tercih ettiği kurumların karșılaştırılması: Türkiye Cumhuriyeti ve Kuzey Kıbris Türk Cumhuriyeti örneği. Journal of Human Sciences, 14(4), 3521-3534. doi:10.14687/ihs.v14i4.4969

Accreditation does not provide benefits to relevant institutions only after they are accredited. Institutions are subject of transformation during the accreditation process. The solutions for the difficulties that may arise during this transformation and the connections and the partnerships have an important value. Accreditation is a guideline for institutions and provides institutions with prestige and confidence as well as features such as idealism, motivation, and faith. Benefits are not only intangible; accreditation increases the mobility of both students and faculty members and strengthens internationalization. There will be many different practices, such as ERASMUS, related to student and lecturers' mobility, and also the signing and cooperation between accredited institutions will be facilitated. So the recognition and image of the accreditation institution gains importance. Even if the education unit is not recognized on an international scale, recognition will increase in proportion to the accreditation institution, because the quality of the accreditation institution guarantees its quality.

There are some educational institutions which are a brand in their area. So for other educational institutions it is an indicator for quality to be able to declare that they are accredited to the same institution. The shareholders can compare thus the institute in which classification the concerned educational unit is. Therefore the accreditation and the accreditation foundation are very important for the educational unit.

A very simple accreditation process does not give meaning for the institution because it does not show any exclusiveness. For exclusivity it should not be too easy for educational units to reach the standards. The standards should procure a better education, international validity and should make it easier to proceed.

In this study, universities operating in the Republic of Turkey and the Turkish Republic of Northern Cyprus and having a Faculty of Business Administration were examined. There are in total 29 faculties of business. One of these is in the Turkish Republic of Northern Cyprus and the others are located in the Republic of Turkey.

Among the Faculty of Business Administration, those who initiate and complete the accreditation process are separated. From these 29 faculties 21 faculties aren't integrated in any accreditation process. Then it was researched to which institutions the relevant faculties are accredited or applied for. As a result, it has emerged that AACSB and IACBE are preferred. Association to Advance Collegiate School of Business, in short AACSB, was founded in 1916; therefore International Assembly for Collegiate Business Education, in short IACBE, was founded in 1997. Despite of IACBE was founded later; it has accredited almost twice business schools. To find out the reason for this the process had to be examined.

The accreditation processes of these two and two other accreditation foundations, their membership fees and the ways in which they publicize themselves are compared with each other. Also the accreditation institutions preferred by the top 10 business schools were examined. It is understood that AACSB was preferred by 70 percent of the top business schools and the process is harder than the other. In addition, when the membership fees of both institutions are compared, it is observed that the annual fee of IACBE is almost half of the AACSB but the application fee is $20 \%$ higher. Even in the first instance the payments that may be incurred during the process are for AACSB two times more than for IACBE. It should not be ignored that AACSB may be expected to undertake more financial incentives in order to achieve these standards throughout the accreditation process, a more formal and accredited accreditation process than the flexible line accreditation process of IACBE. If accreditation is to be regarded as a quality indicator, it should be considered that the institutions preferred by schools that have proved their quality and success worldwide reflect this indicator better. For this reason, accreditation agencies should be assessed with benefits rather than high costs and standards.

The aim of this study is to compare the preferred accreditation institutions in our country with each other and to establish a data base for business faculties who want to be accredited and to provide convenience when choosing an accreditation institution. 